\title{
Returning to periscope depth in a circular control room configuration
}

\author{
Neville A. Stanton ${ }^{1}\left[\right.$ ] $\cdot$ Aaron P. J. Roberts ${ }^{1} \cdot$ Kiome A. Pope $^{1}$ (D $\cdot$ Daniel Fay $^{1}$
}

Received: 18 May 2020 / Accepted: 22 October 2020 / Published online: 11 November 2020

(c) The Author(s) 2020

\begin{abstract}
Previous research has shown that co-location of operators dependent on each other for task-relevant information can relieve the previously identified bottleneck of information between the Sonar Control (SOC) and Operations Officer (OPSO) in submarine sound and control rooms. This research aimed to examine the impact of a novel inwards facing circular configuration on communications and tasks within a co-located control room. Ten teams participated in high and low demand Return to Periscope Depth scenarios in a simulated submarine control room. All communications between operators were recorded and compared with a baseline study of contemporary operation. The findings show that the novel circular configuration led to a reduction in communications, but an increase in information shared. Indicating that the teams had become more efficient at passing relevant information. Furthermore, teams were able to complete a greater number of tasks.
\end{abstract}

Keywords Submarine $\cdot$ Teamwork $\cdot$ Communications $\cdot$ Networks $\cdot$ Control room configuration

\section{Introduction}

\subsection{Contemporary submarine control room design}

Submarine command teams are characteristic of distributed teams due to their reliance on technology to communicate between the separate sound and control rooms (Cramton 2001; Hinds and Bailey 2003; Hamburger et al. 2011; Stanton et al. 2017). In contemporary submarines, Sonar Operators (SOPs) and Target Motion Analysis operators (TMAs) are reliant on the Sonar Controller (SOC) and the Operations Officer (OPSO), to pass information between the sound room and the control room (Roberts et al. 2017a, 2018; Stanton et al. 2017). Passive sonar is the key sensor used when operating at depth (Zarnich 1999; Kirschenbaum et al. 2014). In such scenarios, the SOPs are required to pass on information about contacts such as bearing, course, and speed (Stanton et al. 2017). The distributed nature of the command team means that information exchange is often incomplete or missing entirely (Hinds and Bailey 2003). In a baseline study of a contemporary submarine control room operations,

Neville A. Stanton

n.stanton@soton.ac.uk

1 Human Factors Engineering, Transportation Research Group, University of Southampton, Boldrewood Innovation Campus, Burgess Road, Southampton, UK
Stanton et al. (2017) identified a bottleneck of information between the SOC and the OPSO; the two operators responsible for passing information between the sound and control rooms. Further issues that stem from the distributed nature of the command team include a failure to share uniquely held information (Hinds and Bailey 2003). In a submarine control room, the Officer of the Watch (OOW) is required to assimilate data from disparate sources to maintain safety and make tactical decisions (Dominguez et al. 2006; Roberts et al. 2017a). However, due to the distributed nature of the team and the lower status of the SOPs, critical information such as speed and course estimates may not be being shared in some circumstances, hindering completion of an accurate tactical picture (Hinds and Bailey 2003; Stanton et al. 2017).

While submarine command rooms represent a high state of evolution it does not mean they cannot be improved (Stanton 2014; Stanton and Roberts 2017). Technological advancements such as noise-cancelling headphones mean that the sound and control rooms are no longer required to be separate (Hamburger et al. 2011). A study by Stanton and Roberts (2020a) co-located the SOPs and TMAs in the control room, allowing the operators to communicate with each other about task-relevant information. This co-location configuration enabled greater volumes of communication and greater efficiency in the control room, reducing the previously identified bottleneck between the OPSO and the SOC (Stanton et al. 2017; Stanton and Roberts 2020a, b; 
Roberts et al. 2019). In this study, however, operators still faced the outwards of the control room, preventing face-toface communication that is traditionally associated with colocated teams (Hinds and Bailey 2003; Stanton and Roberts 2020a). Traditionally, the control room was required to be located at the top of the submarine due to the hull penetrating periscope (Stanton and Bessell 2014; Scott 2017). Therefore, operator consoles faced outwards to effectively utilise space (Stanton and Bessell 2014). However, these legacy constraints can now be overcome thanks to technological advancements. Optronic mast systems have removed the requirement for mast penetration through the hull, instead, an electronic cable is required (Scott 2017). This offers greater flexibility in submarine control room location and design, such that the control room could be moved to a wider part of the ship (Hamburger et al. 2011; Scott 2017; Stanton and Roberts 2020a, b). If the control room were to be moved, this would also facilitate incorporating the sound room into the control room (Hamburger et al. 2011). Furthermore, movement of the control room from the top deck to middeck may allow for different configurations of the control room (Hamburger et al. 2011). In the larger space permitted, it would be possible to arrange the operator consoles so that they face inwards in a circular configuration, facilitating face-to-face contact that is characteristic of co-located teams (Hamburger et al. 2011).

\subsection{Circular control room configuration}

From King Arthur's round table (Perkins 2003) to the London 2012 Olympic Stadium (Crockford et al. 2011) circular style physical arrangements have been bringing people together throughout history (Falout 2014). In an analysis of operation room layouts Hendy et al. (2000) concluded that inward-facing layouts were more efficient than an outward-facing layout. In a submarine control room, an inwards facing circular configuration would allow all operators to see each other, and placing the OOW in the centre would ensure they remain central to the command team (Roberts et al. 2019). Furthermore, in a circular configuration the "potential to be commanded" may be increased due to the OOW being able to view facial aspects of operators rather than the backs of their heads; a factor considered by Hendy et al. (2000) when examining operations room layouts. The improved visibility of all operators may facilitate greater coordination within the team, and as such communication would be aided by the addition of facial expressions, gestures, and other non-verbal cues (Hendy et al. 2000). Eye contact, a crucial element of communication, between operators would be permitted, promoting greater cooperation and more favourable attitudes (Argyle and Dean 1965; Wichman 1970; Gardin et al. 1973). The requirement for operators to verbally acknowledge receipt of information may be contributing to the bottleneck of information previously identified in contemporary control rooms (Roberts et al. 2017a, 2018; Stanton et al. 2017). In contemporary submarine control rooms, operators are not able to utilise non-verbal cues such as nodding to indicate understanding (Clark and Brennan 1991). As such operators must verbally confirm the information they receive from other operators, potentially increasing communications in the control room (Cassell et al. 2001), although this does mean that the transmitter of the information knows that it have been received correctly. When operators are unable to see visual cues they interrupt speech more frequently, further inflating communications between operators (Boyle et al. 1994). In a circular configuration, operators will be able to supplement their own communications with non-verbal cues, potentially reducing the number of communications required (McNeill 1992).

With the OOW situated in the centre of the circular configuration not only will they be able to monitor what operators are working on (if slave monitors on the reverse of the workstation are provided), they can also monitor operator workload. From the centre, the OOW may be able to deduce that operators are under high workload from eye movements and facial expressions (Dinges et al. 2005; Ahlstrom and Friedman-Berg 2006; Halverson et al. 2012). High workload is indicated by shorter blink duration and larger mean pupil diameter (Ahlstrom and Friedman-Berg 2006). Furthermore, negative facial expressions (including eyebrow and mouth movements) exhibited by operators may also aid the OOW in determining if an operator is experiencing high workload (Dinges et al. 2005). Submarines of the future are likely to include more advanced sensors and instruments such as Unmanned Underwater Vehicles (UUVs) (Hewish 2002; Stanton and Roberts 2020a). The greater volume of data gathered from these new and improved sensors will be handled by a crew size that is likely to be similar to current requirements or potentially reduced (Masakowski and Hardinge 2000; Roberts et al. 2017b; Fay et al. 2019). Therefore, it is critical that operator workload is maintained at a suitable level for optimal performance (Masakowski 2000). If the OOW is able to monitor operator workload from the centre of the control room they will better be able to decide where additional resource is required and allocate as necessary.

In the current work, the impact of a novel circular control room configuration upon submarine command team performance was examined during high and low demand Return To Periscope Depth (RTPD) scenarios. During a RTPD the command team must use passive sonar to detect and designate all contacts and create a tactical picture before safely returning to periscope depth (Zarnich 1999; Kirschenbaum et al. 2014; Stanton et al. 2017). The current work builds upon previous studies that examined current ways of working during RTPD scenarios (Stanton et al. 2017) and a 
co-located configuration with different crew sizes (Stanton and Roberts 2020a, b). The aim of the current work is to evaluate the circle configuration and secondly to compare the results to the baseline comparator (Stanton et al. 2017).

\section{Methods}

\subsection{Participants}

A total of 10 teams of eight and 10 teams of seven (150 participants total across both studies) were recruited opportunistically from a variety of backgrounds, primarily including undergraduate students and graduate recruits from defence companies and organisations. Ideally, all of the participants in the study would be serving submariners but, as noted in previous research, they are not readily available (Stanton 2020b). Also, teamwork studies of this nature rely upon quite large numbers of participants. Overall, a total of 128 males and 22 females participated with an age range of $18-55$ (Mean $=27.19, \mathrm{SD}=6.56)$ Participants were randomly allocated to one condition based on time of recruitment (baseline studies were run first). In the baseline study, a total of 71 males and 9 females participated with an age range of $18-55($ Mean $=26.83, \mathrm{SD}=8.69)$ and in the experimental (circle configuration) condition a total of 57 males and 13 females participated with an age range of $21-44$ (Mean $=27.54, \mathrm{SD}=4.42$ ). Two teams of participants (one per condition) were submariners from the British Royal Navy (RN). The study protocol received ethical approval from the University of Southampton Research Ethics Committee (Protocol No: 10099) and MODREC (Protocol No: 551/MODREC/14).

\subsection{Equipment: the submarine control room simulator}

A submarine control room simulator, representative of a currently operational RN submarine, with nine networked workstations was built for testing (for full description see Roberts et al. (2015), see Fig. 1a for configuration). The networked workstations included an OOW station, an OPSO station, a SOC station, two SOP stations, two TMA stations, a Periscope station (PERI) and a Ship Control station (SHC). In all studies, the role of the OOW was assumed by an experimenter to guide the scenarios tactically. In the circle condition, the role of SHC was also played by an experimenter. Based upon the findings of baseline studies and input from Human Factors Subject Matter Experts (SMEs) and Submarine operation SMEs the configuration of the control room was changed for the circle condition (see Fig. 1b). All other aspects (e.g. interfaces, scenarios, roles etc.) remained exactly the same in the circle condition to avoid experimental confounds.

Two RTPD scenarios were designed with SME input and programmed in the simulation engine Dangerous Waters (DW) (see Table 1). DW, a software package developed by Sonalysts, featured networked workstations for each of the roles. Contact movements were predetermined to be consistent across all teams and each scenario lasted approximately $45 \mathrm{~min}$. The simulator was equipped with a comprehensive recording suite, including web cameras and ambient microphones, which allowed the recording of all communications that occurred between command team members.

\subsection{Study design}

The independent variables were scenario demand (within subjects), operator role (between subjects-social network), information type (within subjects-information network) and task type (within subjects-task network). Scenario demand was manipulated by contact behaviour (e.g. speed and course changes vs. steady), the number of contacts detectable in the scenario, and area of operation (see Table 1). The design of scenarios was informed by SMEs to be representative of real high and low demand RTPD operations. The dependent variables were static adjacency matrices (social, information and task) derived from the communications that took place between operators within the command team.

When examining the circle configuration independently, the study employed a $2 \times 9$ mixed design (social networks), a $2 \times 14$ repeated measures design (information networks) and a $2 \times 12$ repeated measures design (task networks). When comparing the baseline configuration to the circle configuration the design was extended, employing a $2 \times 2 \times 9$ mixed design (social networks), a $2 \times 2 \times 14$ mixed design (information networks) and a $2 \times 2 \times 12$ repeated measures design (task networks). The study design remained largely constant between the baseline study and the circle configuration study, including the dependent variables. The comparison of the two configurations was between subjects.

\subsection{Procedure}

The procedure was identical for the baseline and circle conditions. Participants attended the submarine simulator for two full days (8 a.m.-5 p.m.). On the first day, informed consent was attained, and a simulator induction was completed. After this, team roles were randomly assigned. The rest of the morning was spent watching a set of general submarine control room operation tutorials, whilst the afternoon was spent watching workstation specific tutorials and practicing tasks both individually and as a functional command 
Fig. 1 Presentation of control room configuration used during baseline and circle configuration. The numbered points highlight the key issues revealed by the baseline studies and how these have been addressed in the circle configuration $\mathbf{a}$
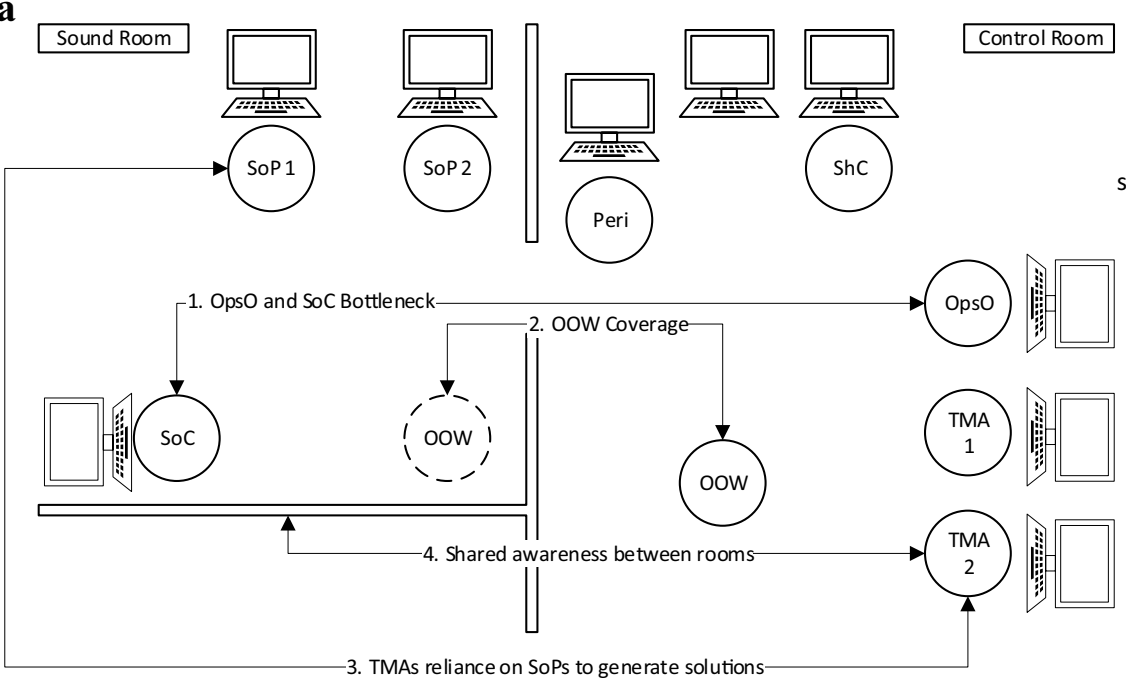

b

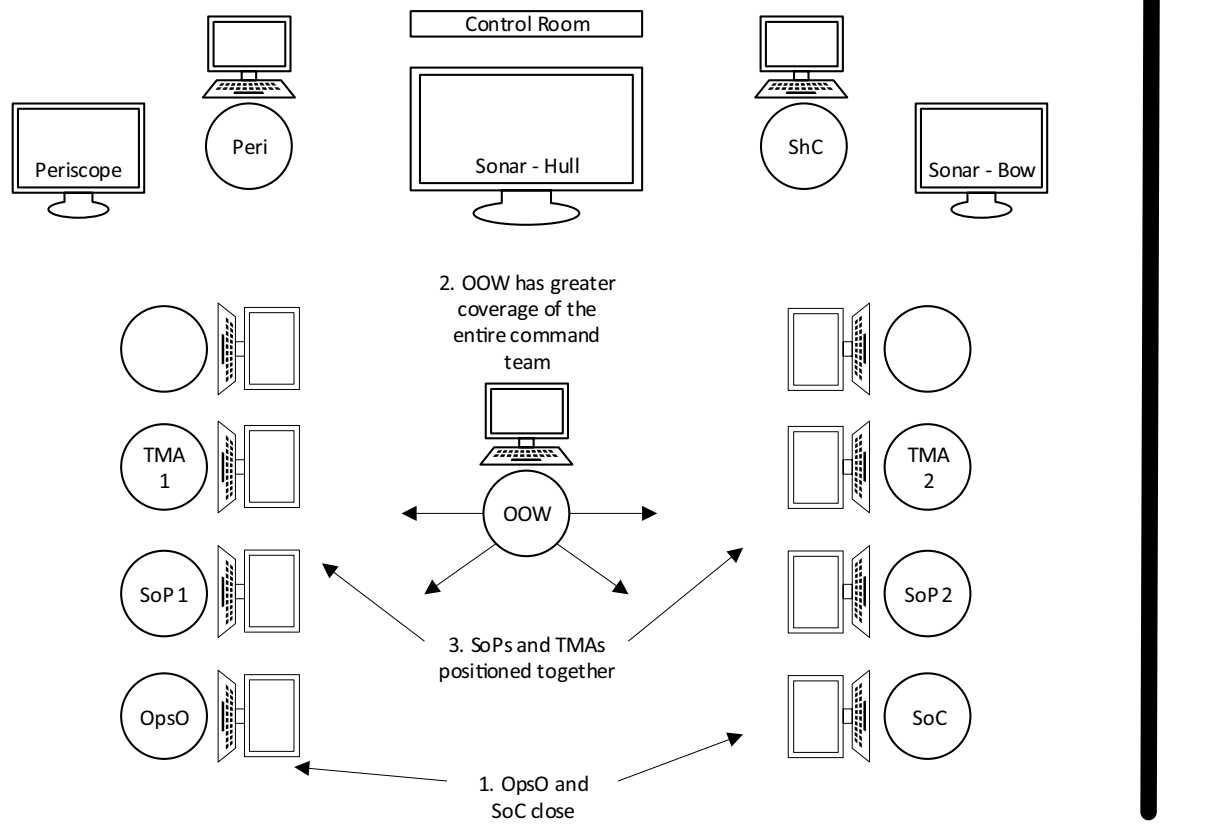

4. Shared awareness between rooms

Table 1 Description of scenarios

\begin{tabular}{lll}
\hline Demand & No. Contacts & Mission \\
\hline Low & 4-Fishing & $\begin{array}{c}\text { RTPD from deep to send intelligence home, large temporal window of opportunity. All contacts held must be } \\
\text { ranged to find optimum course for RTPD. Scenario complete once periscope has marked all contacts }\end{array}$ \\
High & $\begin{array}{l}\text { 9-Fishing } \\
\text { 3-Catamaran } \\
\text { 1-Biological }\end{array}$ & \\
\hline
\end{tabular}




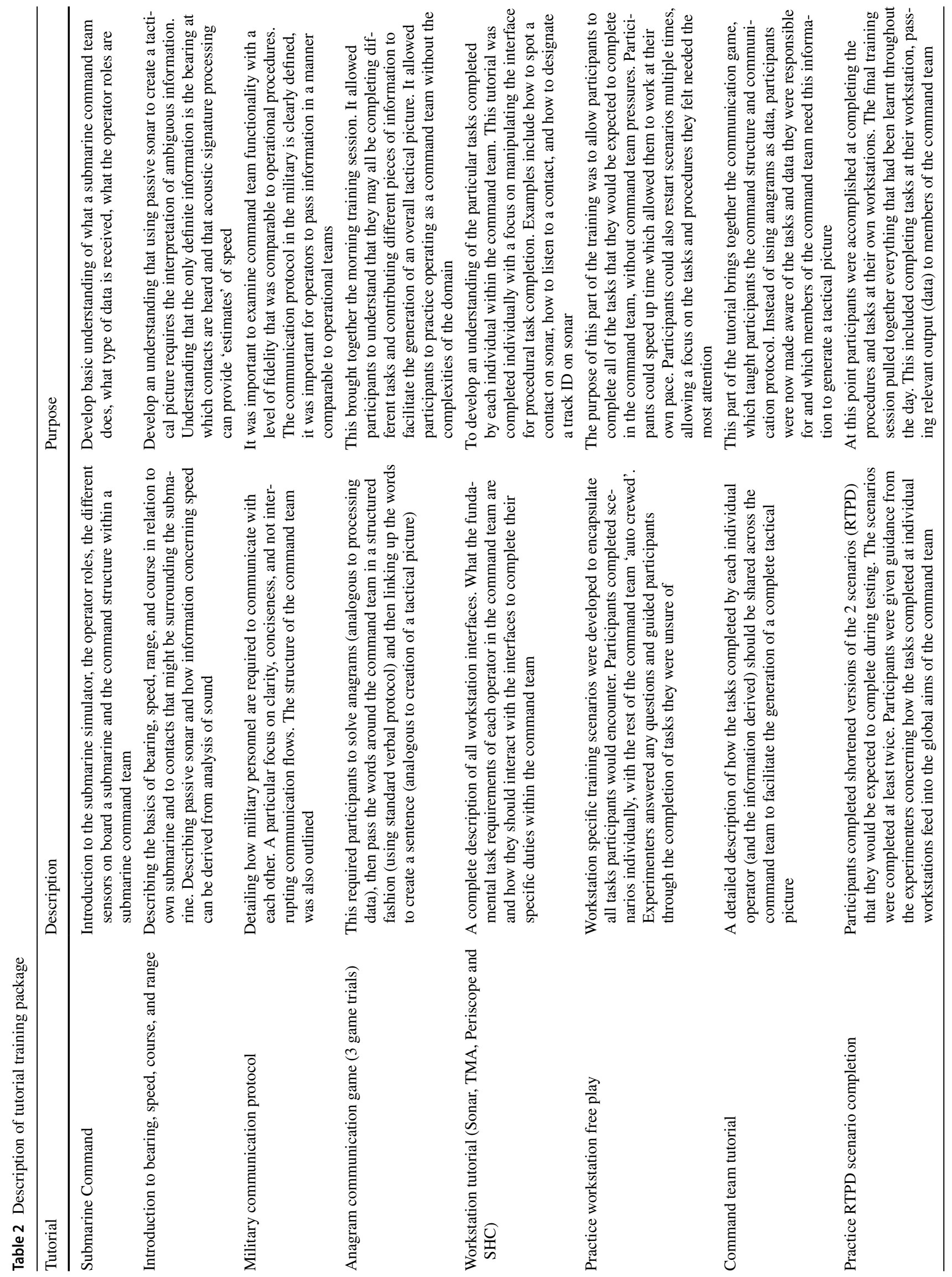


team (see Table 2 for a full description of tutorials). Regular breaks and refreshments were provided between tutorials, which each lasted approximately $45 \mathrm{~min}$. Questions about tasks and operation of workstations as well as the communications protocol were encouraged.

The testing day (second day) started with a refresher training scenario as a functional command team. Performance was monitored by experimenters to ensure all tasks were being completed correctly in line with set criteria provided by SMEs (e.g., steering the submarine safely to relevant courses and depths, adequately detecting surrounding vessels, gaining solutions concerning surrounding vessels, and developing the tactical picture). Following the refresher training, the first scenario was begun-at which point all recording devices were started and a verbal time stamp was read aloud for synchronization purposes. The scenarios began with an OOW briefing outlining the mission objectives (see Table 1). The end of the scenario was called once the mission objective had been achieved. Each team completed both scenarios, occupying the same positions in the command team. To reduce order effects scenario presentation was counterbalanced across the 20 teams. Participants were provided with a short break between scenarios. At the end of the final scenario, participants were provided with a full debrief and thanked for participating.

\subsection{Data analysis}

A new shortened version of Event Analysis for Systemic Teamwork (EAST) (Stanton et al. 2008, 2019) was used for data analysis. EAST examines complex sociotechnical systems using a network approach. This method has been presented in a previous study to model submarine command and control (Stanton 2014) and was used in the baseline study (Stanton et al. 2017; Stanton and Roberts 2020a). The framework has also been applied in other domains such as air traffic control (Walker et al. 2010), aviation (Stewart et al. 2008), emergency services (Houghton et al. 2006), road safety (Salmon et al. 2014), and military risk assessment (Stanton and Harvey 2016). EAST facilitates an understanding of the processes undertaken by a submarine command team having completed an RTPD, utilising a network approach to understand how people, technology, information, and tasks were connected. Social networks analyse communications taking place between 'agents' in the system. Information networks describe the information nodes or 'pieces' that different agents in the system use and communicate during task performance. Finally, task networks describe the relationships between tasks, their sequence and interdependences.

Social, information, and task networks were generated from video and microphone recordings. Leximancer software (version 2.1 -a software program for identifying concepts in text documents) was used to determine the nodes in the information networks. The top 14 information elements (according to frequency count) were included in the statistical analysis, based on the identification of the most important aspects of the task of returning to periscope depth identified in previous studies (Stanton and Roberts 2017, 2020a, b). AGNA software (version 2.1.1-a software program for computing the Social Network metrics) was used to compute whole network metrics (e.g. density, diameter and cohesion) and nodal metrics (e.g. sociometric status and centrality of each node) for all networks (see Table 3 for definitions of all metrics). Data from the novice and expert submariners were combined into one set as previous research has shown that there were quantitative rather than qualitative differences in the activities; expert submarines were able to perform more interactions and complete more tasks than their novice counterparts but they did not undertake fundamentally different activities (Stanton, 2020b).

Data analysis was completed in two stages. Firstly, the circle configuration was examined independently. Dependent $t$ tests were conducted to examine the effect of scenario demand on global network metrics (for social and information networks). Differences in the frequency of task completion between scenarios of high and low demand were examined with $2 \times 12$ (demand $\times$ task nodes) repeated measures Analyses of Variances (ANOVAs). To examine the effect of scenario demand and operator role on social node metrics $2 \times 9$ (demand $\times$ operators) mixed ANOVAs were conducted. To examine the effect of scenario demand and operator role on social node metrics $2 \times 14$ (demand $\times$ information nodes) repeated measures ANOVAs were conducted. In the interests of completeness, the statistical analysis of the baseline tests were reported in the tables, however, the results were not discussed in more detail as they are reported in the baseline studies and are outside of the scope of the current work. All other significant main effects were examined by conducting post hoc pairwise comparisons. To account for multiple comparisons the Bonferroni correction method was used ( $\alpha=0.05 /$ number of comparisons).

In the second stage of analysis, a comparison of the circle to the baseline configuration was examined. For social and information networks $2 \times 2$ (configuration $\times$ demand) mixed ANOVAs were conducted to examine the effect of configuration and scenario demand on global network metrics. For social node metrics, to examine the effect of configuration, scenario demand, and operator role $2 \times 2 \times 9$ (manipulation $\times$ demand $\times$ operators) mixed ANOVAs were conducted. For information node metrics, $2 \times 2 \times 14$ (manipulation $\times$ demand $\times$ information nodes) mixed ANOVAs were conducted to examine the effect of configuration and scenario demand. $2 \times 2 \times 12$ (manipulation $\times$ demand $\times$ task nodes) repeated measures ANOVAs were conducted to 
examine differences in the frequency of task completion based upon configuration and demand. When reporting the results of the configurations comparison main effects of demand were not reported, instead the interactions between demand and manipulation were focused upon, as this was the primary interest of the current work. All statistical analysis was conducted using IBM SPSS v21.

\section{Results}

\subsection{Social network analysis}

In the circle condition, the average frequency of communications between operators in the command team varied depending on command team role and scenario demand (see Fig. 2-key nodes highlighted in black). OPSO had the largest volume of emissions and receptions of all operators, although OOW and TMA1 also had a large number of emissions and receptions, particularly in the high demand scenarios. The overall composition of high and low demand networks is similar, however, the volume of interactions between operators increased during the high demand circle RTPD scenarios.

\subsubsection{Whole network metrics}

In the circle configuration the total interactions $(t(9)=12.18$, $p<0.05, r=0.97)$ statistically significantly increased in the high demand circle condition. The total number of edges $\left(F(1,18)=17.85, p<0.05, \dot{\eta}_{\mathrm{p}}^{2}=0.50\right)$, density $(F(1$, $\left.18)=17.72, p<0.05, \dot{\eta}_{\mathrm{p}}^{2}=0.50\right)$, cohesion $(F(1,18)=5.80$, $\left.p<0.05, \dot{\eta}_{\mathrm{p}}^{2}=0.24\right)$ and total interactions $(F(1,18)=12.18$, $\left.p<0.05, \dot{\eta}_{\mathrm{p}}^{2}=0.51\right)$ of the entire networks were statistically significantly affected by configuration type. This indicates that the structure of the networks fundamentally changed as a result of the new configuration, whilst the new configuration differentially impacted upon network structured based upon scenario demand (see Table 4).

\subsubsection{Nodal metrics}

3.1.2.1 Emissions In the circle configuration the total emissions of each node were statistically significantly affected by scenario demand $\left(F(1,81)=434.98, p<0.01, \dot{\eta}_{\mathrm{p}}^{2}=0.84\right)$ and operator role $\left(F(8,81)=50.93, p<0.01, \dot{\eta}_{\mathrm{p}}^{2}=0.83\right)$. The interaction of scenario demand and role also statistically significantly affected total node emissions $(F(8$, $\left.81)=24.11, p<0.01, \dot{\eta}_{\mathrm{p}}^{2}=0.70\right)$. When examining the effect of scenario demand, post hoc analysis revealed that overall, emissions were statistically significantly higher $(p<0.05)$ in the high demand RTPD condition than the low demand condition. All operators except PERI and SHC had statistically $(p<0.05)$ higher emissions in the high demand condition than the low demand condition. When examining the effect of role post hoc analysis revealed that OPSO had statistically significantly higher $(p<0.05)$ emissions than all other operators (see Table 5; Fig. 2). OOW and SOC had statistically significantly $(p<0.05)$ more emissions than all other operators except TMA1 and TMA2 with whom no significant difference was observed. PERI and SHC had statistically significantly $(p<0.05)$ less emissions than all operators. When examining the interaction between demand and role, post hoc analysis revealed that OOW had statistically significantly $(p<0.05)$ more emissions than SOC, SOP1, SOP2, TMA1, and TMA2 in the low demand condition but not in the high demand condition. OPSO had statistically significantly $(p<0.05)$ more emissions than OOW in the high demand condition but not in the low demand condition. SOP1 and SOP2 had statistically significantly $(p<0.05)$

Table 3 Definitions of global network metrics and node metrics

\begin{tabular}{ll}
\hline Metric & Definition \\
\hline Global & Entities in a network (people, information or tasks for the purposes of this paper) \\
$\begin{array}{l}\text { Nodes } \\
\text { Edges }\end{array}$ & Pairs of connected entities \\
Density & Number of relations observed represented as a fraction of the total relations possible \\
Cohesion & Number of reciprocal connections in the network divided by number of possible connections* \\
Nodal & Number of links emanating from node in the network \\
Emission & Number of links going to each node in the network \\
Reception & Number of emissions and receptions relative to the number of nodes in the network \\
Sociometric & Extent to which network revolves around a single node \\
Centrality &
\end{tabular}

*This is not the same definition used in the teamwork literature on cohesion, which defines team cohesion as a multidimensional concept that includes (but is not limited to) a bonding and closeness between team members and a loyalty to the team (Salas et al. 2015). This may, or may not, include reciprocal communication connections 
Fig. 2 Social network diagrams for low and high demand circle RTPD circle scenarios

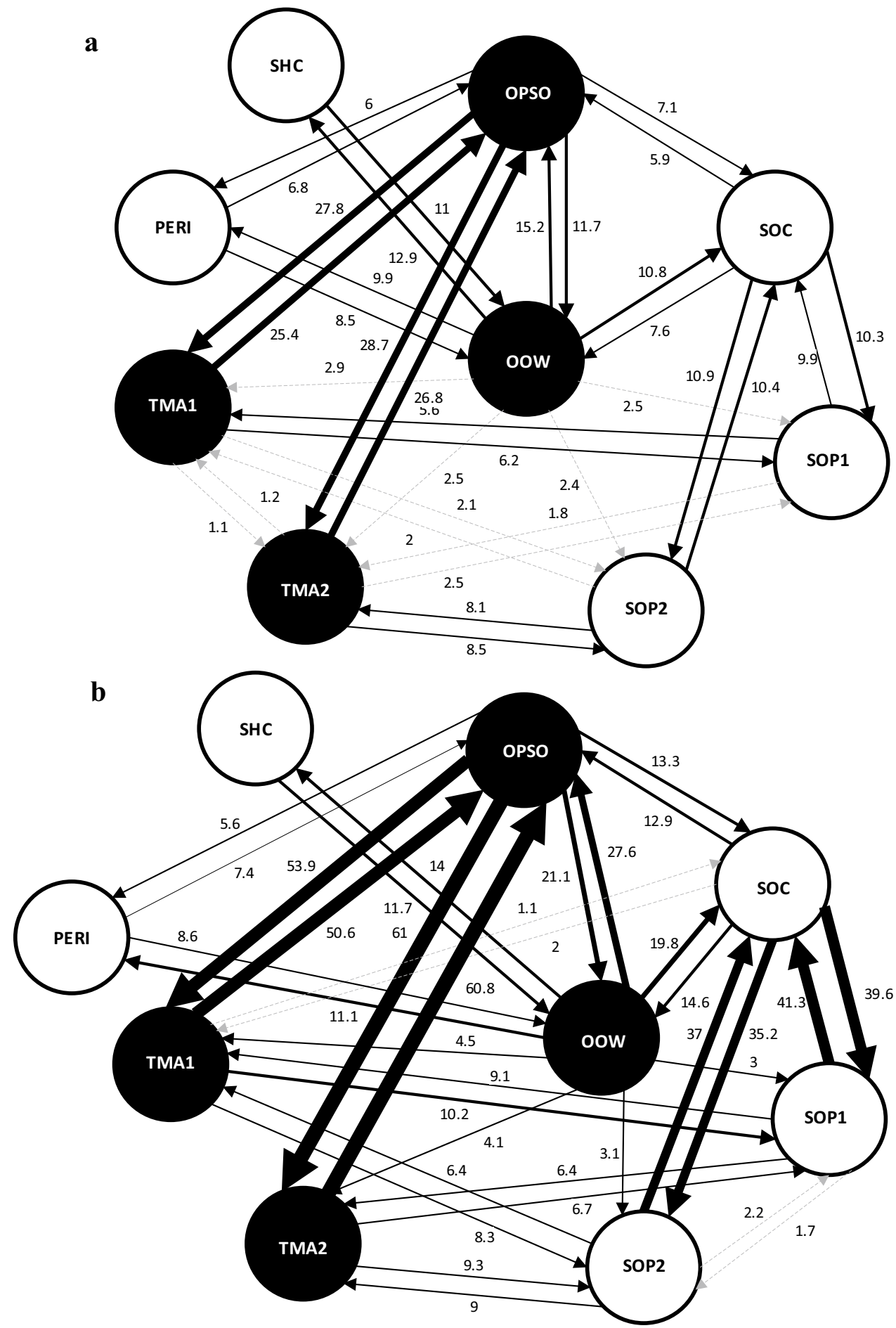

higher emissions than SHC and PERI in the high demand condition but no significant differences were observed in the low demand condition.

The total emissions of each node were statistically significantly affected by configuration type $(F(1,162)=73.20$, $\left.p<0.01, \dot{\eta}_{\mathrm{p}}^{2}=0.31\right)$. The interaction of configuration type and role statistically significantly affected total emissions $\left(F(8,162)=10.42, p<0.01, \dot{\eta}_{\mathrm{p}}^{2}=0.34\right)$. The interaction of configuration type, role, and demand did not statistically significantly affect emissions $(F(8,162)=0.74, p>0.05)$. Further analysis revealed emissions were statistically significantly $(p<0.05)$ lower in the circle configuration compared 
to baseline. Post hoc analysis revealed all operators except TMA1 and TMA2 had statistically significantly $(p<0.05)$ less emissions in the circle configuration than baseline.

3.1.2.2 Receptions In the circle configuration the total receptions of each node were statistically significantly affected by scenario demand $(F(1,81)=482.27, p<0.01$, $\left.\dot{\eta}_{\mathrm{p}}^{2}=0.86\right)$ and operator role $(F(8,81)=54.61, p<0.01$, $\left.\dot{\eta}_{\mathrm{p}}^{2}=0.84\right)$. The interaction of scenario demand and role also statistically significantly affected total node receptions ( $F$ $\left.(8,81)=31.61, p<0.01, \dot{\eta}_{\mathrm{p}}^{2}=0.76\right)$. When examining the effect of scenario demand, post hoc analysis revealed that, overall, receptions were statistically significantly higher $(p<0.05)$ in the high demand RTPD condition than the low demand condition. All operators except PERI and SHC had statistically $(p<0.05)$ higher receptions in the high demand condition than the low demand condition. When examining the effect of role post hoc analysis revealed that OPSO had statistically significantly higher $(p<0.05)$ receptions than all other operators (see Table 5; Fig. 2). SOC had statistically significantly $(p<0.05)$ more receptions than all other operators except TMA1 and TMA2 with whom no significant difference was observed. PERI and SHC had statistically significantly $(p<0.05)$ less receptions than all operators. When examining the interaction between demand and role post hoc analysis revealed that SOP1 and SOP2 had statistically significantly $(p<0.05)$ higher receptions than SHC and PERI in the high demand condition but no significant differences were observed in the low demand condition.

The total receptions of each node were statistically significantly affected by configuration type $(F(1,162)=81.46$, $\left.p<0.01, \dot{\eta}_{\mathrm{p}}^{2}=0.34\right)$. The interaction of configuration type and role statistically significantly affected total receptions $\left(F(8,162)=10.11, p<0.05, \dot{\eta}_{\mathrm{p}}^{2}=0.33\right)$. The interaction of configuration type, role and demand did not statistically significantly affect receptions $(F(8,162)=0.85, p>0.05)$. Further analysis revealed receptions were statistically significantly $(p<0.05)$ lower in the circle configuration compared to baseline. Post hoc analysis revealed all operators except,
TMA1, TMA2, SHC, and PERI had SOC had statistically significantly $(p<0.05)$ less receptions in the circle configuration compared to baseline.

3.1.2.3 Sociometric status In the circle configuration the sociometric status of each node was significantly affected by scenario demand $\left(F(1,81)=491.13, p<0.01, \dot{\eta}_{\mathrm{p}}^{2}=0.86\right)$ and operator role $\left(F(8,81)=54.72, p<0.01, \dot{\eta}_{\mathrm{p}}^{2}=0.84\right)$. The interaction of scenario demand and role also statistically significantly affected sociometric status $(F(8,81)=29.52$, $\left.p<0.01, \dot{\eta}_{\mathrm{p}}^{2}=0.75\right)$. When examining the effect of scenario demand, post hoc analysis revealed overall, sociometric status was statistically significantly higher $(p<0.05)$ in the higher demand RTPD condition than the low demand condition. All operators except PERI and SHC had statistically significantly higher sociometric status in the high demand condition than the low demand condition. When examining the effect of operator role post hoc analysis revealed OPSO had statistically significantly $(p<0.05)$ higher sociometric status than all other operators. OOW and SOC had statistically significantly $(p<0.05)$ higher sociometric status than all other operators, except TMA1 and TMA2, with who no significant differences were observed. PERI and SHC had statistically significantly $(p<0.05)$ lower sociometric status than all other operators. When examining the interaction of demand and role post hoc analysis revealed SOC had statistically significantly $(p<0.05)$ higher sociometric status than SOP1 and SOP2 in the high demand condition but no significant difference was observed in the low demand condition.

The sociometric status of each node was statistically significantly affected by configuration type $(F(1,162)=82.73$, $\left.p<0.05, \dot{\eta}_{\mathrm{p}}^{2}=0.34\right)$ and the interaction of configuration type and role $\left(F(8,162)=10.96, p<0.01, \dot{\eta}_{\mathrm{p}}^{2}=0.35\right)$. The interaction of configuration type, role and demand, did not significantly affect sociometric status $(F(8,162)=0.72, p>0.05)$. Further analysis revealed sociometric status was statistically significantly $(p<0.05)$ lower in the circle configuration compared to baseline. Post hoc analysis revealed OOW, OPSO, and SOC had statistically significantly $(p<0.05)$ lower

Table 4 Social network metrics for whole network RTPD baseline and circle configuration

\begin{tabular}{|c|c|c|c|c|c|c|}
\hline & \multicolumn{4}{|l|}{ RTPD } & \multirow{3}{*}{$\begin{array}{l}\text { Effect of Demand ( } t \\
\text { Value) Circle configura- } \\
\text { tion only }\end{array}$} & \multirow{3}{*}{$\begin{array}{l}\text { Effect } \\
\text { of Con- } \\
\text { figuration }(F \\
\text { value) }\end{array}$} \\
\hline & \multicolumn{2}{|c|}{ Baseline configuration } & \multicolumn{2}{|c|}{ Circle configuration } & & \\
\hline & Low & High & Low & High & & \\
\hline Nodes & 9 & 9 & 9 & 9 & NA & NA \\
\hline Edges & $36.80 \pm 3.01$ & $36.50 \pm 4.93$ & $30.90 \pm 3.41$ & $32.70 \pm 2.54$ & 1.48 & $17.85 * * *$ \\
\hline Density & $0.51 \pm 0.04$ & $0.51 \pm 0.07$ & $0.42 \pm 0.06$ & $0.45 \pm 0.04$ & 1.77 & $17.72 * * *$ \\
\hline Cohesion & $0.34 \pm 0.03$ & $0.35 \pm 0.03$ & $0.36 \pm 0.04$ & $0.39 \pm 0.04$ & 1.43 & $5.80 *$ \\
\hline Diameter & $3.00 \pm 0.00$ & $2.80 \pm 0.42$ & $3.00 \pm 0.00$ & $3.00 \pm 0.00$ & 0.00 & 2.25 \\
\hline Total Interactions & $663.80 \pm 206.32$ & $816.10 \pm 221.10$ & $314.30 \pm 47.28$ & $638.80 \pm 95.13$ & $12.18 * * *$ & $18.89 * * *$ \\
\hline
\end{tabular}




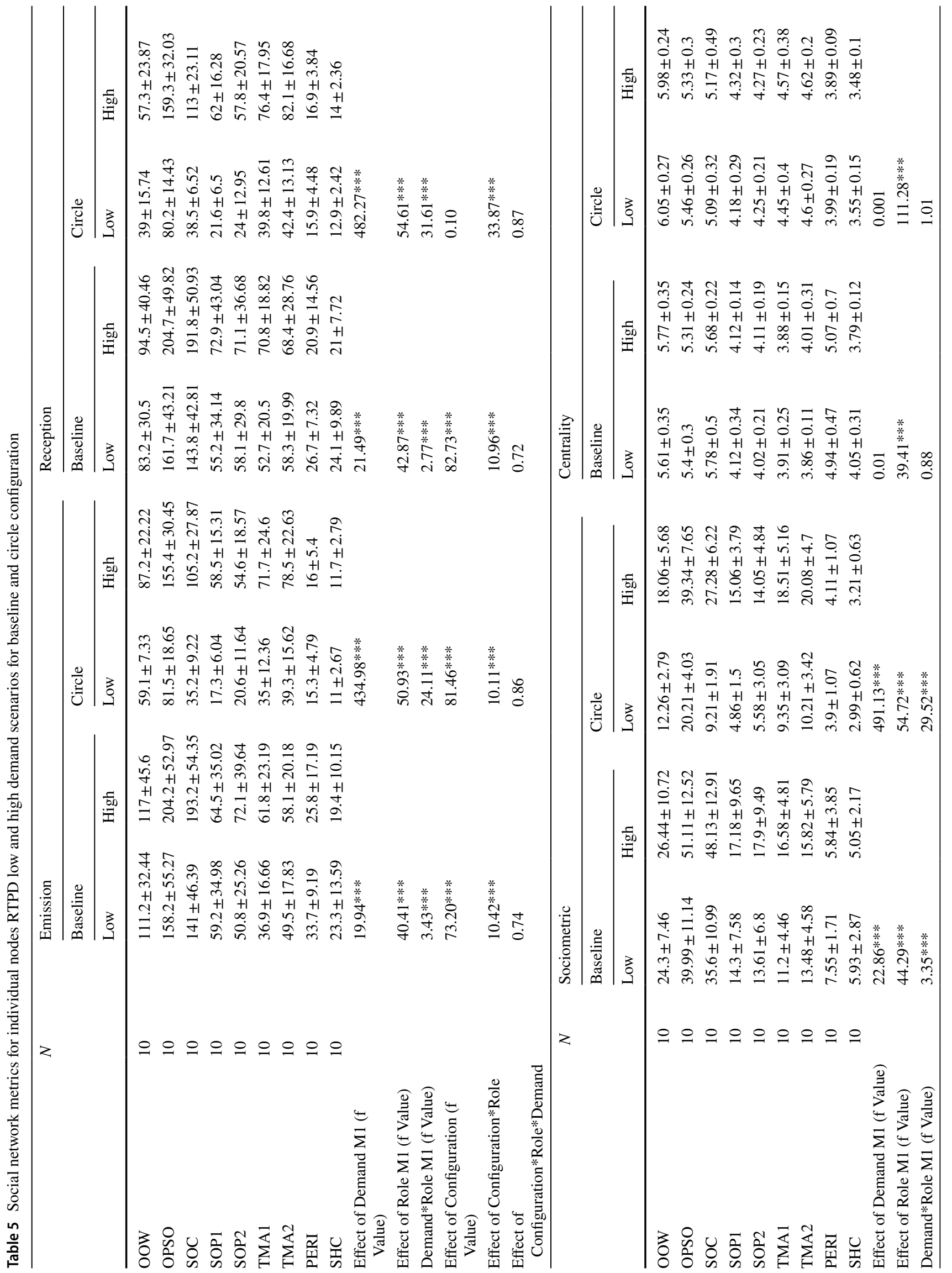




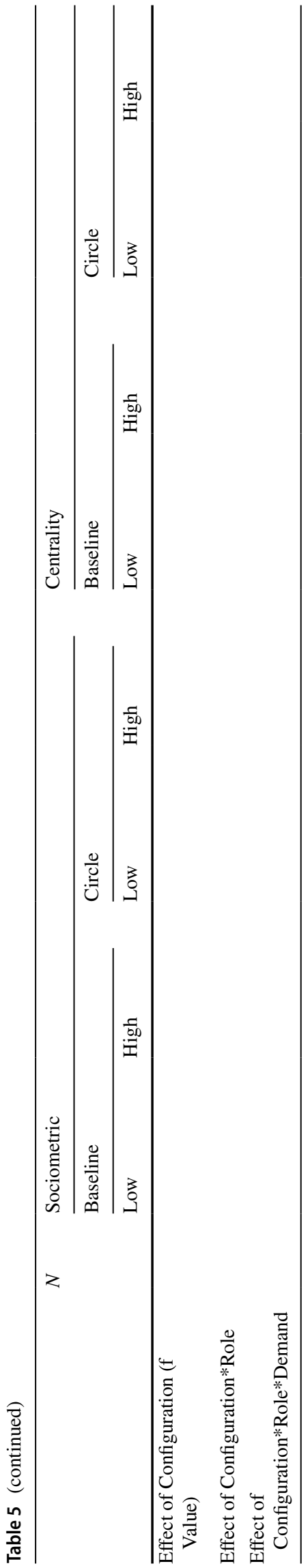

sociometric status in the circle configuration than in the baseline condition.

3.1.2.4 Centrality The centrality of each node was not statistically significantly affected by scenario demand $(F$ (1, $81)=0.10, p>0.05)$ but was significantly affected by operator role $\left(F(8,81)=111.28, p<0.01, \eta_{p}^{2}=0.92\right)$, although no significant interaction between scenario demand and role $(F(8,81)=1.02, p>0.05)$ was observed. When examining the effect of role post hoc analysis revealed OOW had statistically significantly $(p<0.05)$ higher centrality than all operators. OPSO and SOC had statistically significantly higher centrality than all operators (except OOW). SHC had statistically significantly $(p<0.05)$ lower centrality than all other operators.

The centrality of each node was not statistically significantly affected by configuration type $(F(1,162)=0.10$, $p>0.05)$ or the interaction of configuration type, role and demand $(F(8,162)=0.87, p>0.05)$. The interaction of configuration type and role statistically significantly affected sociometric status $\left(F(8,162)=33.87, p<0.01, \dot{\eta}_{\mathrm{p}}^{2}=0.63\right)$. Post hoc analysis revealed OOW and SOC had statistically significantly $(p<0.05)$ higher centrality in the circle configuration than in baseline. TMA1, TMA2, and PERI had statistically significantly $(p<0.05)$ lower centrality in the circle configuration compared to baseline.

\subsection{Information network analysis}

In the circle configuration the structure of the information networks is relatively consistent in both high and low demand RTPD scenarios with 'contact', 'bearing' and 'course' the most connected information pieces (see Fig. 3). The volume of emissions from most information elements appeared to increase in the high demand RTPD scenarios although differences in relationships can be observed.

\subsubsection{Whole network metrics}

In the circle configuration statistically significantly more emissions $(t(9)=4.68, p<0.05, r=0.84)$, nodes $(t(9)=6.81, p<0.05, r=0.92)$ and edges $(t(9)=4.69$, $p<0.05, r=0.84)$ in the high demand condition compared to low demand (see Table 6), indicating that the overall structure of information varied based upon scenario demand. Configuration statistically significantly affected the number of edges $\left(F(1,18)=4.69, p<0.01, \dot{\eta}_{\mathrm{p}}^{2}=0.21\right)$, diameter $(F$ $\left.(1,18)=5.49, p<0.01, \dot{\eta}_{\mathrm{p}}^{2}=0.23\right)$, and network density $(F$ $\left.(1,18)=25.91, p<0.01, \eta_{\mathrm{p}}^{2}=0.59\right)$. The number of edges and network density was statistically significantly $(p<0.05)$ lower in the circle configuration compared to baseline but the diameter of the networks was higher. Indicating that the 
a
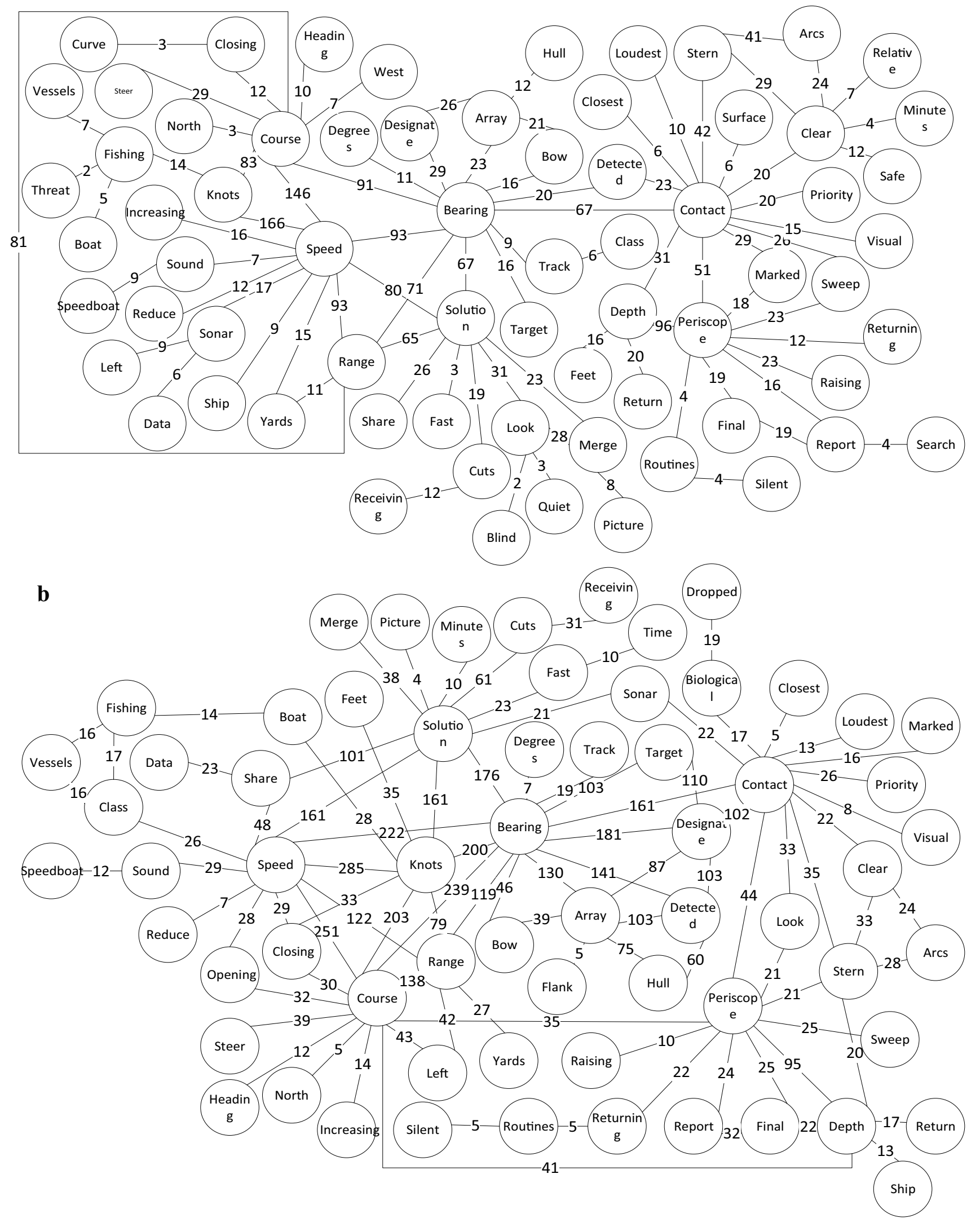

Fig. 3 Information networks RTPD circle configuration high and low demand 
Table 6 Information network Metrics for entire network RTPD circle and baseline

\begin{tabular}{|c|c|c|c|c|c|c|c|}
\hline & \multicolumn{2}{|l|}{ Baseline } & \multicolumn{2}{|l|}{ Circle } & \multirow{2}{*}{$\begin{array}{l}\text { ffect of } \\
\text { Demand } \\
(t \text { Value })\end{array}$} & \multirow{2}{*}{$\begin{array}{l}\text { Effect of } \\
\text { configu- } \\
\text { ration }(\boldsymbol{F} \\
\text { value) }\end{array}$} & \multirow{2}{*}{$\begin{array}{l}\text { Demand*configuration } \\
\text { value }\end{array}$} \\
\hline & Low & High & Low & High & & & \\
\hline Nodes & $45.60 \pm 5.10$ & $44.40 \pm 6.46$ & $40.1 \pm 5.2$ & $47.5 \pm 3.54$ & $6.81 * * *$ & 0.44 & $8.92 * * *$ \\
\hline Edges & $702.10 \pm 330.28$ & $644.80 \pm 357.54$ & $372.4 \pm 100.4$ & $529.6 \pm 123.23$ & $4.69 * * *$ & $4.69 *$ & $4.51 *$ \\
\hline Density & $0.49 \pm 0.15$ & $0.49 \pm 0.19$ & $0.24 \pm 0.03$ & $0.24 \pm 0.04$ & 0.31 & $25.91 * * *$ & 0.00 \\
\hline Diameter & $3.30 \pm 0.82$ & $3.5 \pm 0.53$ & $4 \pm 0.82$ & $4 \pm 0.67$ & 0.00 & $5.49 *$ & 0.27 \\
\hline Total Emissions & $2412.10 \pm 1424.21$ & $2898.90 \pm 2620.68$ & $1209.6 \pm 384.77$ & $1919.6 \pm 509.44$ & $4.68 * * *$ & $3.16^{\mathrm{t}}$ & 0.14 \\
\hline
\end{tabular}

circle configuration changed the structure of the information networks.

\subsubsection{Nodal metrics}

3.2.2.1 Emissions In the circle configuration the total emissions of each node were statistically significantly affected by scenario demand $\left(F(1,126)=171.73, p<0.01, \dot{\eta}_{\mathrm{p}}^{2}=0.58\right)$ and concept type $\left(F(13,126)=27.77, p<0.01, \dot{\eta}_{\mathrm{p}}^{2}=0.62\right)$. A statistically significant $(F(13,126)=14.41, p<0.01$,

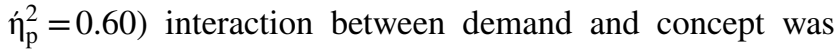
also observed. Emissions were statistically significantly higher $(p<0.05)$ in the high demand RTPD condition than the low demand condition. Further analysis revealed bearing had statistically significantly $(p<0.05)$ more emissions than all other information except course and speed. Course and speed had statistically significantly $(p<0.05)$ more emissions than all other information except contact, solution, and range. Bearing, contact, course, solution, speed, and range had statistically significantly more emissions in the high demand scenarios compared to the low demand (see Table 7).

The total emissions of each node were statistically significantly affected by configuration type $(F(1,252)=35.53$, $\left.p<0.05, \dot{\eta}_{\mathrm{p}}^{2}=0.12\right)$. The total number of emissions were statistically significantly $(p<0.05)$ lower in the circle configuration.

3.2.2.2 Receptions In the circle configuration the total receptions of each node were statistically significantly affected by scenario demand $(F(1,126)=171.73, p<0.01$, $\left.\grave{\eta}_{\mathrm{p}}^{2}=0.58\right)$ and concept type $(F(13,126)=27.77, p<0.01$, $\left.\grave{\eta}_{\mathrm{p}}^{2}=0.74\right)$. A statistically significant $(F(13,126)=14.41$, $\left.p<0.01, \eta_{\mathrm{p}}^{2}=0.60\right)$ interaction between demand and concept was also observed. Receptions were statistically significantly higher $(p<0.05)$ in the high demand RTPD condition than the low demand condition. Further analysis revealed bearing had statistically significantly $(p<0.05)$ more receptions than all other information except course and speed. Course and speed had statistically significantly $(p<0.05)$ more receptions than all other information except contact, solution, and range. Bearing, contact, course, solution, speed, and range had statistically significantly more receptions in the high demand scenarios compared to the low demand. The total receptions of each node were statistically significantly affected by configuration type ( $F$ $\left.(1,252)=34.57, p<0.05, \dot{\eta}_{\mathrm{p}}^{2}=0.12\right)$. The total number of receptions were statistically significantly $(p<0.05)$ lower in the circle configuration.

3.2.2.3 Sociometric status In the circle configuration the sociometric status of each node was statistically significantly affected by scenario demand $(F(1,126)=97.41, p<0.01$, $\left.\dot{\eta}_{\mathrm{p}}^{2}=0.44\right)$ and concept type $(F(13,126)=28.96, p<0.01$, $\left.\dot{\eta}_{\mathrm{p}}^{2}=0.75\right)$. A statistically significant $(F(13,126)=10.85$, $\left.p<0.05, \eta_{\mathrm{p}}^{2}=0.53\right)$ interaction between demand and concept was also observed. Sociometric status was statistically significantly higher $(p<0.05)$ in the high demand RTPD condition than the low demand condition. Further analysis revealed bearing had statistically significantly $(p<0.05)$ higher sociometric status than all other information except course and speed. Course and speed had statistically significantly $(p<0.05)$ higher sociometric status than all other information except contact, solution, and range. Bearing, course, solution, and range had statistically significantly higher sociometric status in the high demand scenarios compared to the low demand scenarios.

The sociometric status of each node was statistically significantly affected by configuration type $(F(1,252)=36.77$, $\left.p<0.01, \dot{\eta}_{\mathrm{p}}^{2}=0.13\right)$. A statistically significant interaction between configuration, information type and demand $(F(1$, $\left.252)=1.76, p<0.01, \dot{\eta}_{\mathrm{p}}^{2}=0.08\right)$ was also observed. Sociometric status was statistically significantly $(p<0.05)$ lower in the circle configuration. The sociometric status of bearing, course, and solution was statistically significantly $(p<0.05)$ lower in the circle configuration low demand scenarios compared to the baseline low demand scenarios. The sociometric status of sonar and speed was statistically significantly $(p<0.05)$ lower in the circle configuration high demand scenarios compared to the baseline high demand scenarios. 


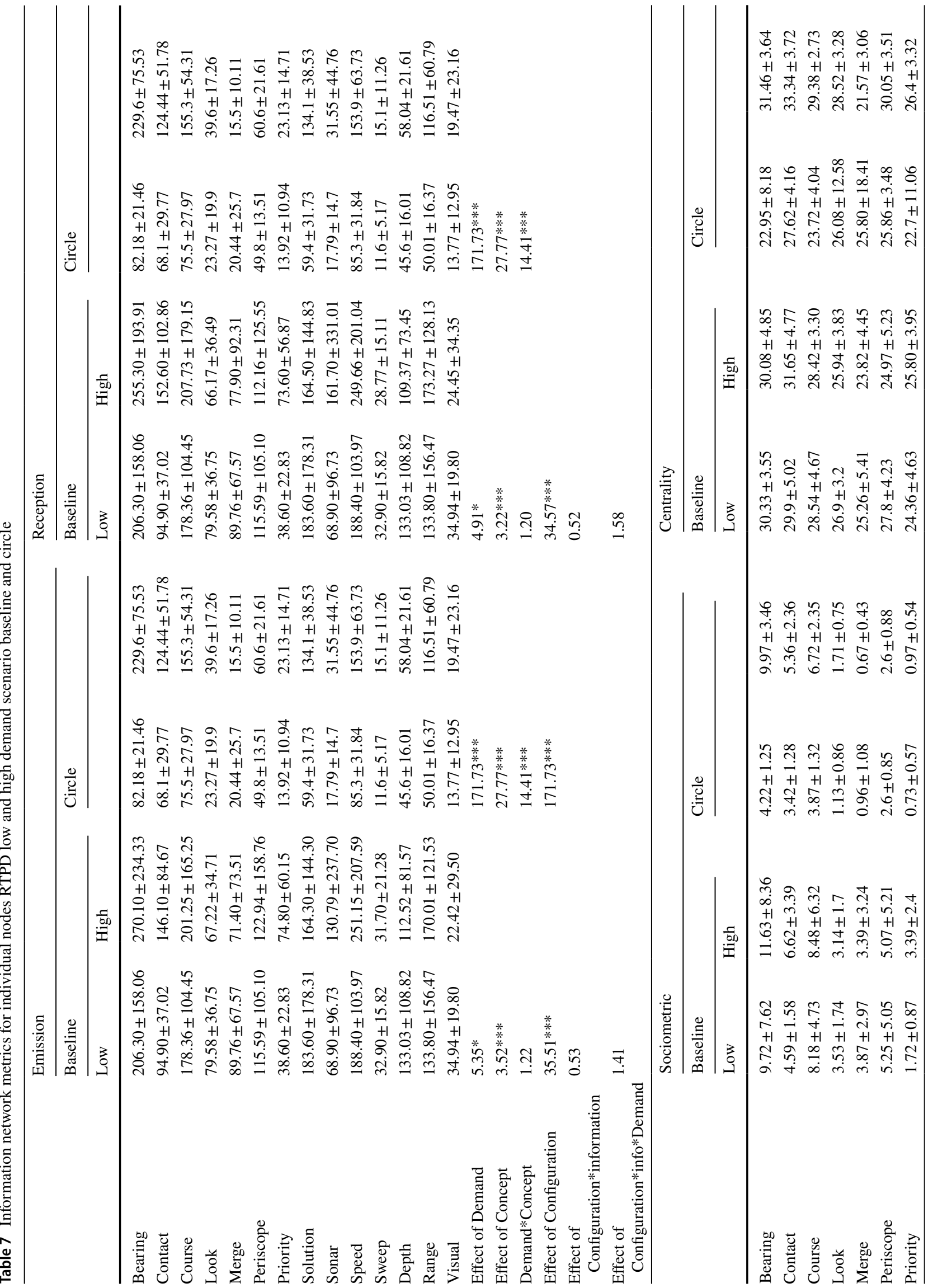




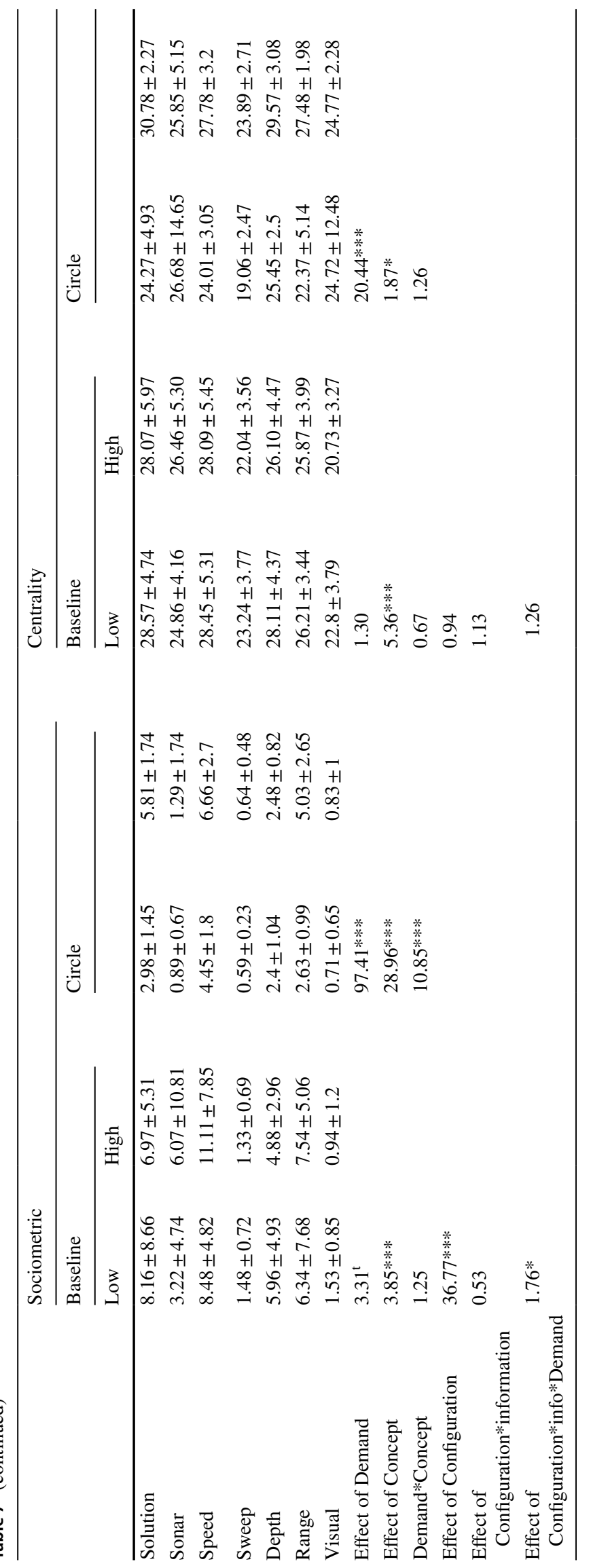


3.2.2.4 Centrality In the circle configuration the centrality status of each node was statistically significantly affected by scenario demand $\left(F(1,126)=20.44, p<0.01, \dot{\eta}_{\mathrm{p}}^{2}=0.14\right)$ and concept type $\left(F(13,126)=1.87, p<0.05, \dot{\eta}_{\mathrm{p}}^{2}=0.16\right)$. In the high demand scenarios centrality was statistically significantly $(p<0.05)$ higher compared to the low demand. Further analysis revealed contact had statistical significantly $(p<0.05)$ higher sociometric status than sweep.

\subsection{Task network analysis}

The type of tasks completed by the command team was the same during the baseline and the circle configuration (for both high and low demand scenarios) as the fundamental task completed by operators did not change. The command team were required to complete a variety of subtasks (e.g. detect and designate sonar contacts), to build a sonar picture that promotes awareness of surrounding contacts, before a submarine is permitted to RTPD (see Fig. 4).

The task with the highest number of emissions was 'building the sonar picture' which required the completion of numerous subtasks (i.e. data analysis and assimilation) to inform the generation of a tactical picture when operating at depth (see Table 8). The verification of tasks networks by SMEs provided the basis for the completion of task frequency analysis.

\subsubsection{Task frequency analysis}

In the circle configuration the frequency of task completion was statistically significantly affected by scenario demand $\left(F(1,189)=290.72, p<0.01, \dot{\eta}_{\mathrm{p}}^{2}=0.61\right)$ and task type $(F$ $\left.(20,189)=43.34, p<0.01, \dot{\eta}_{\mathrm{p}}^{2}=0.82\right)$. A statistically significant interaction $\left(F(20,189)=31.59, p<0.01, \dot{\eta}_{\mathrm{p}}^{2}=0.77\right)$ between scenario demand and task type was also observed. Post-hoc analysis revealed the frequency of task completion was statistically significantly higher $(p<0.05)$ in the high demand condition than the low demand condition. The tasks detecting, designating, classifying, checking cuts, and generating solutions from sonar were completed statistically significantly $(p<0.05)$ more frequently in the high demand condition. Further analysis revealed the tasks of detecting, designating, classifying, generating speed estimates, and generating (and refining) solution estimates from sonar were completed statistically significantly $(p<0.05)$ more frequently than all other tasks (see Table 9). Further analysis revealed the tasks of detecting, designating, generating speed estimates, and generating solutions from sonar were completed statistically significantly $(p<0.05)$ more frequently than classifying sonar contacts, refining solutions, and making changes to own submarines parameters in the high demand condition but not in the low demand condition (see Table 9).

The frequency of task completion was statistically significantly affected by configuration $(F(1,378)=7.07, p<0.01$, $\left.\dot{\eta}_{\mathrm{p}}^{2}=0.43\right)$, the interaction of configuration and task type ( $F$ $\left.(20,378)=4.71, p<0.01, \dot{\eta}_{\mathrm{p}}^{2}=0.20\right)$ and the interaction of configuration, task type and demand $(F(20,378)=6.52$, $\left.p<0.01, \eta_{\mathrm{p}}^{2}=0.26\right)$. Further analysis revealed statistically significantly $(p<0.05)$ more tasks were completed in the circle configuration than the baseline configuration. The tasks detecting and designating on sonar were completed statistically significantly $(p<0.05)$ more frequently in the circle configuration compared to baseline. The tasks of detecting sonar contacts, checking cuts, designating sonar contacts and completing sonar merges were completed statistically significantly $(p<0.05)$ more frequently in the high demand circle configuration than in the baseline high demand scenarios. The task of classifying and generating course estimates for sonar contacts was completed statistically significantly $(p<0.05)$ more frequently in the baseline high demand scenarios compared to the circle configuration baseline scenarios.

\subsection{Summary of results}

As the previous sections have shown, for most of the team process measures (i.e., social network analysis, information network analysis and task network analysis) performance was superior in the inward-looking, circle, configuration when compared to the traditional two-room layout of the control room. In addition, when speaking with the expert submariners immediately after testing the circle configuration, the following comments were elicited:

- "The layout is better than I was expecting and is a step towards improving the flow of information and communication between team members"

- "Realistic circular style control room with massive potential for future development. Advancing how submariners will carry out their jobs in the future."

- "The circular layout allows for a lot of non-verbal information to be passed."

- "The set up and feel of the room is a vast improvement form the baseline setup [Traditional two-room layout]. This current configuration feels like a good submarine control room layout, thus ensuring all tasks were competed successfully."

- "The new trainer set up is an improvement and I feel this would be a good setup for future control rooms. Having contact with everyone in the control room helps to build a picture. I think this is a good way to all face inwards and for the OOW to see what is going on." 
Fig. 4 Task network diagrams for RTPD low and high demand scenarios (baseline and circle configuration)

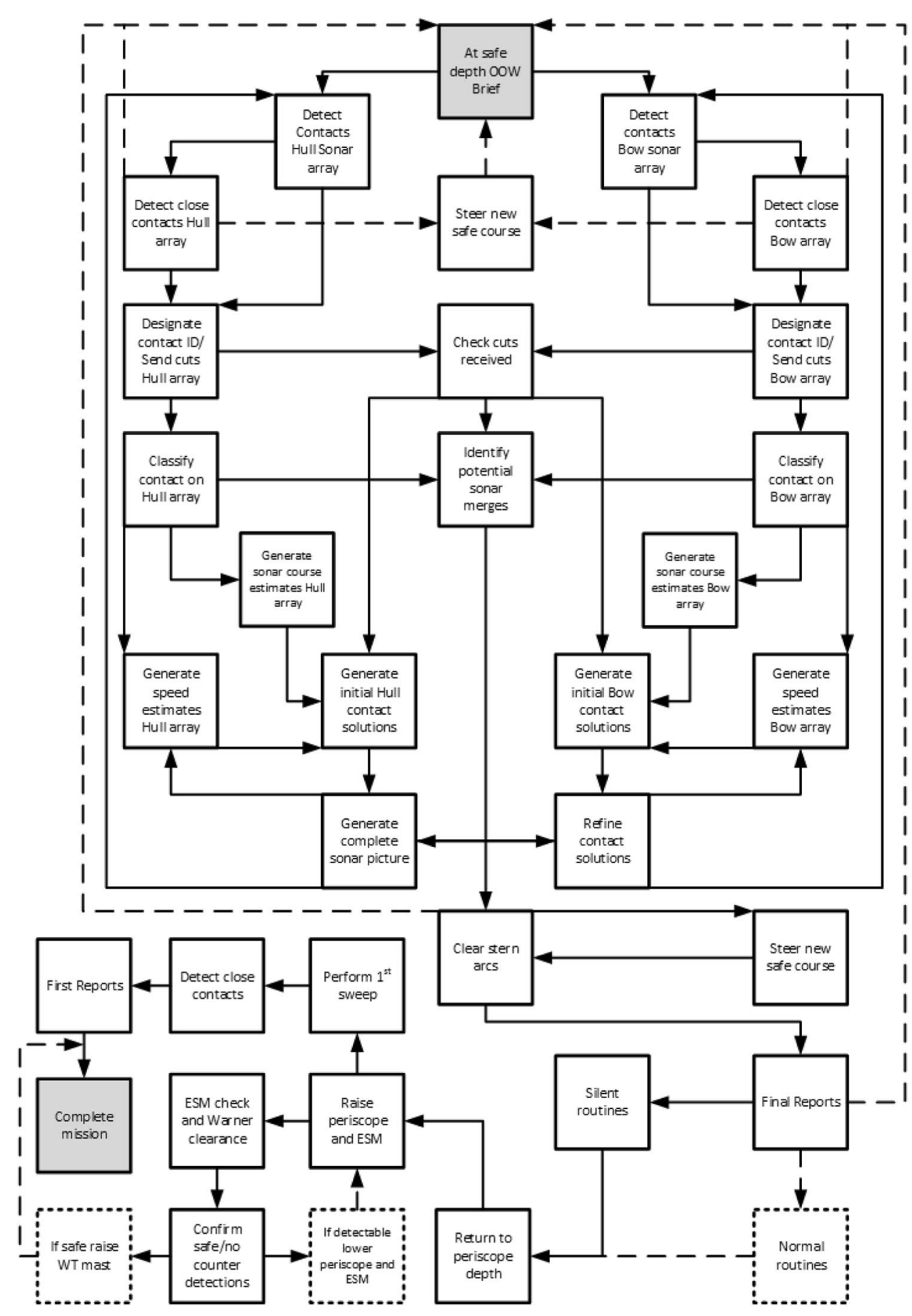

- "New layout has improved communication between OOW/OPS and all outstations. Does provide the ability to communicate non-verbally which in certain situations (e.g., RTPD) is extremely useful."

In summary, the expert submariners were very favourable in their comments on the new inward-facing, circle, configuration of the control room an opined that it was superior to the traditional, two-room, layout.

\section{Discussion}

In the circle configuration, operators coped with an increase in demand by increasing the total number of communications; similar to what had been observed previously in the baseline configuration and the co-location study (Stanton et al. 2017; Stanton and Roberts 2020a, b). This was to be expected due to the greater number of contacts the command team were required to manage in the high demand scenario. 
Table 8 Task network metrics for individual nodes RTPD scenarios high and low demand scenarios (baseline and circle configuration)

\begin{tabular}{|c|c|c|c|c|c|c|c|c|}
\hline & Emission & Reception & Sociometric & Centrality & Closeness & Farness & Betweeness & Eccentricity \\
\hline OOW brief & 1 & 4 & 0.19 & 11.18 & 0.16 & 159 & 40.00 & 12 \\
\hline Detect contacts sonar & 3 & 2 & 0.19 & 12.59 & 0.19 & 134 & 69.23 & 11 \\
\hline Close sonar contact & 3 & 2 & 0.19 & 14.04 & 0.22 & 120 & 73.71 & 10 \\
\hline Designate sonar contact & 2 & 2 & 0.15 & 11.35 & 0.17 & 153 & 77.00 & 12 \\
\hline Classify Sonar Contacts & 3 & 1 & 0.15 & 11.72 & 0.19 & 137 & 41.04 & 11 \\
\hline Speed estimates & 1 & 3 & 0.15 & 11.07 & 0.17 & 157 & 3.50 & 11 \\
\hline Sonar Courses & 1 & 1 & 0.08 & 10.29 & 0.17 & 154 & 0.50 & 11 \\
\hline Identify sonar merges & 2 & 2 & 0.15 & 12.24 & 0.21 & 124 & 68.35 & 10 \\
\hline Check cuts are received & 2 & 1 & 0.12 & 11.35 & 0.18 & 143 & 33.96 & 11 \\
\hline Build Sonar Picture & 4 & 1 & 0.19 & 12.96 & 0.25 & 104 & 36.45 & 9 \\
\hline Generate Solutions & 1 & 3 & 0.15 & 12.66 & 0.20 & 133 & 63.65 & 10 \\
\hline Steer safe course & 2 & 2 & 0.15 & 13.04 & 0.21 & 126 & 49.00 & 9 \\
\hline Refine solutions & 3 & 3 & 0.23 & 14.14 & 0.24 & 109 & 121.05 & 9 \\
\hline Clear Stern arcs & 2 & 3 & 0.19 & 13.52 & 0.21 & 125 & 174.56 & 8 \\
\hline Final Reports & 3 & 1 & 0.15 & 14.23 & 0.24 & 108 & 174.00 & 7 \\
\hline Silent Routines & 1 & 1 & 0.08 & 22.13 & 0.68 & 38 & 75.00 & 6 \\
\hline Normal Routines & 1 & 1 & 0.08 & 22.13 & 0.68 & 38 & 75.00 & 6 \\
\hline RTPD & 1 & 2 & 0.12 & 20.67 & 0.93 & 28 & 153.00 & 5 \\
\hline Raise Periscope & 2 & 2 & 0.15 & 18.11 & 1.37 & 19 & 158.00 & 4 \\
\hline 1st Sweep & 1 & 1 & 0.08 & 16.85 & 4.33 & 6 & 54.00 & 3 \\
\hline Detect Close Visual & 1 & 1 & 0.08 & 14.61 & 8.67 & 3 & 34.00 & 2 \\
\hline First Reports & 1 & 1 & 0.08 & 12.74 & 26.00 & 1 & 12.00 & 1 \\
\hline ESM check & 1 & 1 & 0.08 & 15.01 & 1.00 & 26 & 69.00 & 6 \\
\hline Confirm Submarine safe & 2 & 1 & 0.12 & 13.78 & 1.24 & 21 & 56.00 & 5 \\
\hline Raise WT mast & 1 & 1 & 0.08 & 13.61 & 26.00 & 1 & 12.00 & 1 \\
\hline Lower Periscope & 1 & 1 & 0.08 & 12.17 & 1.08 & 24 & 9.00 & 5 \\
\hline Complete mission & 0 & 2 & 0.08 & 11.59 & 0.00 & 0 & 0.00 & 0 \\
\hline
\end{tabular}

The total number of interactions, number of edges, and density of the social networks was significantly lower in the circle configuration, with total interactions in the circle high demand comparable to those of the baseline low demand (Stanton et al. 2017). This indicates that the command team were communicating less frequently, between fewer operators, meaning that the social network was less cluttered. However, in the circle configuration cohesion was significantly greater, indicating that, despite fewer interactions, the network was actually more connected. It appears that the co-location element of the circular configuration has reduced the bottleneck between the OPSO and SOC, with emissions from these operators seeing the greatest reduction (Stanton et al. 2017; Stanton and Roberts 2020a, b). This frees these operators to focus on overseeing the work of the TMAs and SOPs rather than passing information between the TMAs and SOPs (Stanton et al. 2017; Stanton and Roberts 2020a, b). The inwards facing design with duplicate work screens allowed all operators to see what each other was working on, and potentially receive information without verbally requesting it (Clark and Brennan 1991; McNeill 1992). This design permitted face-to-face communication between operators that is characteristic of traditional co-located teams (Hamburger et al. 2011). This may have facilitated the reduction in communications due to the potential to use non-verbal cues (Boyle et al. 1994; Hendy et al. 2000; Cassell et al. 2001).

The emissions and receptions of all operators were reduced in the circle configuration, with the exception of TMA1 and TMA2 in the high demand scenario. It may be that the circle configuration facilitated a greater number of communications by these operators as they were able to request information when they needed it, from the operator they needed it from. In the circle configuration, the sociometric status of the more senior operators (OOW, OPSO, SOC) was significantly lower than in the baseline study (Stanton et al. 2017). This may reflect the fact that the bottleneck of information between these operators was reduced meaning that information was able to flow around them, rather than through them. Despite this, the centrality of the OOW, OPSO, and SOC was still greater than all other operators, highlighting their importance to command room operations (Stanton et al. 2017). A key issue with the 
Table 9 Frequency of task completion RTPD scenarios baseline and circle configuration

\begin{tabular}{|c|c|c|c|c|}
\hline \multirow[t]{3}{*}{ Demand } & \multicolumn{4}{|l|}{ RTPD } \\
\hline & \multicolumn{2}{|l|}{ Baseline } & \multicolumn{2}{|l|}{ Circle } \\
\hline & Low & High & Low & High \\
\hline Detect sonar contacts & $4 \pm 1.89$ & $8.7 \pm 4.22$ & $2.9 \pm 0.74$ & $17.6 \pm 5.15$ \\
\hline Designate sonar contacts & $3.3 \pm 1.64$ & $7.7 \pm 4.85$ & $3.4 \pm 1.78$ & $14.2 \pm 2.86$ \\
\hline Classify sonar contacts & $3.8 \pm 1.87$ & $10.5 \pm 4.3$ & $1.9 \pm 1.52$ & $6.8 \pm 3.79$ \\
\hline Sonar speed estimates & $5.4 \pm 2.27$ & $10.9 \pm 5.67$ & $5.4 \pm 2.5$ & $9.2 \pm 4.98$ \\
\hline Sonar course estimates & $1.2 \pm 1.23$ & $4.9 \pm 2.13$ & $2.4 \pm 1.96$ & $2.6 \pm 2.55$ \\
\hline Check cuts & $2.4 \pm 1.84$ & $3.9 \pm 1.52$ & $2.3 \pm 1.16$ & $8.6 \pm 3.57$ \\
\hline Sonar merges & $3.4 \pm 1.35$ & $2.8 \pm 1.81$ & $2.7 \pm 1.06$ & $6.7 \pm 1.57$ \\
\hline Sonar solution & $4.6 \pm 1.96$ & $10.7 \pm 3.53$ & $4 \pm 0.47$ & $12.6 \pm 3.47$ \\
\hline Refine solutions & $4.2 \pm 3.58$ & $5.1 \pm 3.63$ & $5.3 \pm 1.95$ & $7.7 \pm 3.47$ \\
\hline Change submarine parameters & $4.4 \pm 2.46$ & $4.3 \pm 2.06$ & $3.7 \pm 1.06$ & $3.8 \pm 1.14$ \\
\hline Raise periscope & $1 \pm 0$ & $0.8 \pm 0.42$ & $1.1 \pm 0.32$ & $1.1 \pm 0.32$ \\
\hline Complete sweep & $1.8 \pm 0.63$ & $0.8 \pm 0.42$ & $1.2 \pm 1.03$ & $1.3 \pm 0.67$ \\
\hline Detect visual contacts & $1.7 \pm 0.95$ & $1.4 \pm 1.07$ & $2.4 \pm 1.17$ & $3.2 \pm 1.48$ \\
\hline Designate visual contacts & $1.3 \pm 1.06$ & $1.1 \pm 1.1$ & $1.8 \pm 1.48$ & $2.7 \pm 2$ \\
\hline Classify visual contacts & $0.7 \pm 0.82$ & $1.1 \pm 2.02$ & $0.1 \pm 0.32$ & $0 \pm 0$ \\
\hline Range visual contacts & $0.8 \pm 1.03$ & $1.6 \pm 2.5$ & $0.2 \pm 0.42$ & $0.4 \pm 0.7$ \\
\hline Course estimates of visual & $0.4 \pm 0.97$ & $1 \pm 2.83$ & $0.2 \pm 0.42$ & $0.5 \pm 1.27$ \\
\hline Visual solutions & $0.1 \pm 0.32$ & $0.1 \pm 0.32$ & $0 \pm 0$ & $0 \pm 0$ \\
\hline Merge visual and sonar & $0.7 \pm 0.82$ & $0.3 \pm 0.95$ & $0.1 \pm 0.32$ & $0 \pm 0$ \\
\hline Clear stern arcs & $1 \pm 0$ & $1 \pm 0.47$ & $1 \pm 0$ & $1.1 \pm 0.32$ \\
\hline Final reports & $1 \pm 0$ & $0.9 \pm 0.32$ & $1 \pm 0$ & $1 \pm 0$ \\
\hline Effect of demand & $57.41 * * *$ & & $290.72 * * *$ & \\
\hline Effect of task type & $25.20 * * *$ & & $43.34 * * *$ & \\
\hline Demand $*$ task & $7.09 * * *$ & & $31.59 * * *$ & \\
\hline Effect of Configuration & $7.07 * * *$ & & & \\
\hline Effect of Configuration*task & $4.71 * * *$ & & & \\
\hline Effect of Configuration*Task*Demand & $6.52 * * *$ & & & \\
\hline
\end{tabular}

co-location studies previously conducted was that the OOW was on the periphery of the command team (Stanton and Roberts 2020a, b; Roberts et al. 2019). In the current work, the OOW was in a central position as so was able to observe all operators and tasks being conducted. As the OOW was central to the information flow, both verbally and visually, they were able to troubleshoot more effectively.

In the circle configuration, the top 14 concepts remained the same as in the baseline study, indicating that the circle configuration had not affected the type of information most important to the RTPD operation (Stanton et al. 2017). When examining the information networks, there were significantly more nodes, edges, and total emissions in the high demand scenario, suggesting that as well as communicating more frequently in response to demand, operators also communicated a wider range of information. This effect of demand was not observed in the baseline study (Stanton et al. 2017) but was observed when operators dependent on each other for task-relevant information were co-located
(Stanton and Roberts 2020a). The density of the information networks was significantly lower in the circle configuration compared to the baseline study. As task-dependent operators were co-located in the circle configuration they were able to request information when it was required. Therefore, communications contained only the necessary information and were not passed by multiple operators (Stanton and Roberts 2020a). Furthermore, as emissions and receptions of concepts were statistically significantly lower in the circle configuration, it seems that the increase in total emissions came from additional information that was not able to be provided during the baseline study, rather than repetition of key concepts.

The type of tasks completed by the command team was the same during the circular configuration and the baseline study as the task completed by operators did not change. When examining the effect of scenario demand on task completion in the circle configuration, results were comparable to the baseline study, with more tasks being completed in 
the high demand scenario due to the greater number of contacts the command team were required to manage (Stanton et al. 2017). Overall, a significantly greater number of tasks were completed in the circle configuration compared to the baseline study, in particular, the tasks of detection and designation of contacts. These tasks form the foundation of all other sonar tasks and are key for maintaining awareness of vessels surrounding own-ship (Stanton 2014). It appears that the inwards facing circular configuration increased overall productivity and was well-liked by the expert submariners.

There are two potential limitations associated with this research, however, which are the use of novice submariner participants and the lack of objective measures of performance. As noted earlier, whilst it might be ideal to have 10 teams of serving submariners this is not practically achievable given current operational demands on the Royal Navy. Whilst there is a case to be made for single team studies (Stanton and Roberts 2020b) for the purposes of statistical analysis greater numbers are required. Previous research has shown that the expert teams are faster and complete more task than their novice counterparts but they do not undertake fundamental different activities (Stanton and Roberts, 2017, 2020a). Whist the study reported in this paper focused on the team processes (i.e., communications between team members, information exchanged and tasks performed) it did not report on team performance in terms of tactical picture accuracy. Future research needs to develop robust methods for analysing the accuracy of the tactical picture and reporting on the effects of different control room configurations. It is anticipated the inward-facing, circular, configuration tactical picture would be as least as good as the traditional, two-room, layout. Given that more information was conveyed and more tasks were completed in the inward-facing, circular, configuration it is hoped that the tactical picture accuracy would be improved.

\section{Summary and conclusions}

The current work compared an inward-facing circular configuration to a contemporary outwards facing submarine control room during the completion of high and low demand RTPD scenarios. The novel circular configuration led to a more cohesive command team who communicated in a more concise manner, exchanging a greater volume of information and completing a greater number of tasks. As observed previously, the co-location of the operators dependent on each other for task-relevant information relieved the bottleneck of information between the OPSO and the SOC (Stanton and Roberts 2020a, b; Roberts et al. 2019). The inwards facing, circular, design permitted face-to-face communication between operators that is characteristic of traditional co-located teams (Hamburger et al. 2011). This may have facilitated the reduction in communications due to the potential to use non-verbal cues (Boyle et al. 1994; Hendy et al. 2000; Cassell et al. 2001).

Acknowledgements This work was supported in part by the Underwater Systems Programme of the UK Ministry of Defence Science \& Technology Research Programme, contract TIN3.113. Any views expressed are those of the authors and do not necessarily represent those of the Ministry of Defence or any other UK government department. The authors would like to thank Joy Richardson from the University of Southampton for their help with the collection and transcription of data. The authors would also like to thank the crew members of HMS Trenchant of the Royal Navy, CPO (SSM) D.M. Keyes of the Royal Navy, and Christopher Parnell of the Defence Science and Technology Laboratory for their help and guidance.

Funding This work was supported in part by the Underwater Systems Programme of the UK Ministry of Defence Science \& Technology Research Programme, contract TIN3.113. Any views expressed are those of the authors and do not necessarily represent those of the Ministry of Defence or any other UK government department.

\section{Compliance with ethical standards}

Conflict of interest The authors declare that they have no conflict of interest.

Open Access This article is licensed under a Creative Commons Attribution 4.0 International License, which permits use, sharing, adaptation, distribution and reproduction in any medium or format, as long as you give appropriate credit to the original author(s) and the source, provide a link to the Creative Commons licence, and indicate if changes were made. The images or other third party material in this article are included in the article's Creative Commons licence, unless indicated otherwise in a credit line to the material. If material is not included in the article's Creative Commons licence and your intended use is not permitted by statutory regulation or exceeds the permitted use, you will need to obtain permission directly from the copyright holder. To view a copy of this licence, visit http://creativecommons.org/licenses/by/4.0/.

\section{References}

Ahlstrom U, Friedman-Berg FJ (2006) Using eye movement activity as a correlate of cognitive workload. Int J Ind Ergon 36:623-636. https://doi.org/10.1016/j.ergon.2006.04.002

Argyle M, Dean J (1965) Eye-contact, distance and affiliation. Sociometry 28:289-304

Boyle EA, Anderson AH, Newlands A (1994) The effects of visibility on dialogue and performance in a cooperative problem solving task. Lang Speech 37:1-20

Cassell J, Bickmore T, Campbell L et al (2001) More than just a pretty face: conversational protocols and the affordances of embodiment. Knowl Based Syst 14:55-64. https://doi.org/10.1016/S0950 -7051(00)00102-7

Clark HH, Brennan SE (1991) Grounding in communication. Perspect Soc Shar Cogn 13:127-149

Cramton CD (2001) The mutual knowledge problem and its consequences for dispersed collaboration. Org Sci 12:346-371. https:// doi.org/10.1287/orsc.12.3.346.10098 
Crockford I, Breton M, Mccormick F, Johnson P (2011) Delivering London 2012: the Olympic stadium. Proc Inst Civ Eng Civ Eng 164:37-43. https://doi.org/10.1680/cien.2011.164.6.37

Dinges DF, Rider RL, Dorrian J et al (2005) Optical computer recognition of facial expressions associated with stress induced by performance demands. Aviat Sp Environ Med 76

Dominguez C, Long WG, Miller TE, Wiggins SL (2006) Design directions for support of submarine commanding officer decision making. In: Proceedings of 2006 Undersea HSI symposium: research, acquisition and the warrior, pp 6-8

Falout J (2014) Circular seating arrangements: approaching the social crux in language classrooms. Stud Second Lang Learn Teach 2:275-300. https://doi.org/10.14746/ssllt.2014.4.2.6

Fay D, Stanton NA, Roberts APJ (2019) All at sea with user interfaces: from evolutionary to ecological design for submarine combat systems. Theor Issues Ergon Sci 20:632-658. https://doi. org/10.1080/1463922X.2019.1582115

Gardin H, Kaplan KJ, Firestone IJ, Cowan GA (1973) Proxemic effects on cooperation, attitude, and approach-avoidance in a Prisoner's Dilemma game. J Pers Soc Psychol 27:13

Halverson T, Estepp J, Christensen J, Monnin J (2012) Classifying workload with eye movements in a complex task. Proc Hum Factors Ergon Soc. https://doi.org/10.1177/1071181312561012

Hamburger P, Miskimens D, Truver S (2011) It is not just hardware and software, anymore! Human systems integration in US submarines. Nav Eng J 123:41-50. https://doi.org/10.111 1/j.1559-3584.2009.00198.x

Heath C, Luff P (1991) Collaborative activity and technological design: Task coordination in London Underground control rooms. In: Proceedings of the Second European conference on computer-supported cooperative work ECSCW'91. Springer, pp 65-80

Hendy KC, Edwards JL, Beevis D, Hamburger T (2000) Analysing advanced concepts for operations room layouts. Proc XIVth Trienn Congr Int Ergon Assoc 44th Annu Meet Hum Factors Ergon Assoc'Ergonomics New Millenn 514-517. https://doi. org/10.1177/154193120004403617

Hewish M (2002) Submarines to cast off their shackles, take on new roles. Int Def Rev

Hinds PJ, Bailey DE (2003) Out of sight, out of sync: understanding conflict in distributed teams. Org Sci. https://doi.org/10.1287/ orsc.14.6.615.24872

Houghton RJ, Baber C, McMaster R et al (2006) Command and control in emergency services operations: a social network analysis. Ergonomics 49:1204-1225

Khan A, Matejka J, Fitzmaurice G, Kurtenbach G (2005) Spotlight: directing users' attention on large displays. In: Proceedings of the SIGCHI conference on Human facotrs in computing systems. ACM, pp 791-798

Kirschenbaum SS, Trafton JG, Schunn CD, Trickett SB (2014) Visualizing uncertainty: the impact on performance. Hum Factors 56:509-520

MacMillan J, Paley MJ, Entin EB, Entin EE (1999) Questionnaires for distributed assessment of team mutual awareness. In: Stanton NA, Hedge A, Brookhuis KA et al (eds) Handbook of human factors and ergonomics methods. CRC Press, Boca Raton, FL, pp 484-494

Masakowski YR (2000) Optimized Manning for the 21st Century. In: 36th IAMPS, pp 173-176

Masakowski YR, Hardinge N (2000) Comparing the cognitive decison-making strategies of US and UK Naval Sonar operators. 36th IAMPS. Split, Croatia, pp 167-172

McNeill D (1992) Guide to gesture classification, transcription, and distribution. Hand and mind what gestures reveal about thought. The University of Chicago Press, Chicago, pp 75-104

Perkins D (2003) King Arthur's round table: how collaborative conversations create smart organizations. Wiley, Amsterdam
Roberts APJ, Stanton NA, Fay D (2015) The command team experimental test-bed stage 1: design and build of a submarine command room simulator. Proc Manuf 3:2800-2807

Roberts APJ, Stanton NA, Fay D (2017a) Land ahoy! Understanding submarine command and control during the completion of inshore operations. Hum Factors 59:1263-1288

Roberts APJ, Stanton NA, Fay D (2017b) The command team experimental test-bed phase two: assessing cognitive load and situation awareness in a submarine control room. In: Stanton NA, Landry S, Di Bucchianico G, Vallicelli A (eds) Advances in human aspects of transportation. Advances in intelligent systems and computing. Springer, Cham, pp 427-437

Roberts APJ, Stanton NA, Fay D (2018) Go deeper, go deeper: understanding submarine command and control during the completion of dived tracking operations. Appl Ergon 69:162-175

Roberts APJ, Stanton NA, Fay D, Pope KA (2019) The effects of team co-location and reduced crewing on team communication characteristics. Appl Ergon 81:102875. https://doi.org/10.1016/j.aperg o.2019.102875

Salas E, Grossman R, Hughes AM, Coultas CW (2015) Measuring team cohesion: observations from the science. Hum Fact 57(3):365-374

Salmon PM, Lenné MG, Walker GH et al (2014) Using the Event Analysis of Systemic Teamwork (EAST) to explore conflicts between different road user groups when making right hand turns at urban intersections. Ergonomics 57:1628-1642. https://doi.org/10.1080/00140 139.2014.945491

Scott R (2017) Leaving the periscope behind: optronic masts transform the above-water picture. Jane's Navy Int 122:22

Stanton NA (2014) Representing distributed cognition in complex systems: how a submarine returns to periscope depth. Ergonomics $57: 403-418$

Stanton NA, Bessell K (2014) How a submarine returns to periscope depth: analysing complex socio-technical systems using Cognitive Work Analysis. Appl Ergon 45:110-125

Stanton NA, Harvey C (2016) Beyond human error taxonomies in assessment of risk in sociotechnical systems: a new paradigm with the EAST "broken-links" approach. Ergonomics 60:221-233. https:// doi.org/10.1080/00140139.2016.1232841

Stanton NA, Roberts APJ (2017) Examining social, information, and task networks in submarine command and control. IEEE Trans Hum Mach Syst 48:252-265. https://doi.org/10.1109/THMS.2017.27206 59

Stanton NA, Roberts APJ (2020a) Block off: an examination of new control room configurations and reduced crew sizes examining engineered production blocking. Cogn Technol Work 22:29-55. https:// doi.org/10.1007/s10111-019-00542-x

Stanton NA, Roberts APJ (2020b) Better together? Investigating new control room configurations and reduced crew size in submarine command and control. Ergonomics 63:307-323. https://doi. org/10.1080/00140139.2019.1654137

Stanton NA, Baber C, Harris D (2008) Modelling command and control: event analysis of systemic teamwork. CRC Press, Boca Raton, FL

Stanton NA, Roberts APJ, Fay D (2017) Up periscope: understanding submarine command and control teamwork during a simulated return to periscope depth. Cogn Technol Work 19:399-417. https:// doi.org/10.1007/s10111-017-0413-7

Stanton NA, Salmon PM, Walker GH (2019) Systems thinking in practice: applications of the event analysis of systemic teamwork method. CRC Press, Boca Raton

Stewart R, Stanton NA, Harris D et al (2008) Distributed situation awareness in an Airborne Warning and Control System: application of novel ergonomics methodology. Cogn Technol Work 10:221-229. https://doi.org/10.1007/s10111-007-0094-8

Walker GH, Stanton NA, Baber C et al (2010) From ethnography to the EAST method: a tractable approach for representing distributed 
cognition in Air Traffic Control. Ergonomics 53:184-197. https:// doi.org/10.1080/00140130903171672

Wichman H (1970) Effects of isolation and communication on cooperation in a two-person game. J Pers Soc Psychol 16:114-120. https:// doi.org/10.1037/h0029845

Zarnich RE (1999) A fresh look at broadband passive sonar processing. In: adaptive sensor array processing workshop, Office of Naval Research, pp. 99-104
Publisher's Note Springer Nature remains neutral with regard to jurisdictional claims in published maps and institutional affiliations. 